Arq. Bras. Med. Vet. Zootec., v.71, n.4, p.1286-1292, 2019

\title{
Análise da integridade funcional dos espermatozoides de Tayassu pecari por diferentes soluções hiposmóticas e osmolaridades
}

\author{
[Analysis of the functional integrity of Tayassu pecari sperm by different hyposmotic \\ solutions and osmolarities]
}

\author{
C.H.S.C. Barros, W.M. Machado, R.L.A. Vieira, I.B. Allaman, \\ S.L.G. Nogueira-Filho, P.P.N. Snoeck
}

Universidade Estadual de Santa Cruz - Ilhéus, BA

Celso Henrique Souza Costa Barros https://orcid.org/0000-0003-3440-1593 William Morais Machado https://orcid.org/0000-0002-0134-1478 Renan Luiz Albuquerque Vieira https://orcid.org/0000-0001-8472-0432 Ivan Bezerra Allaman https://orcid.org/0000-0003-0883-0466 Sérgio Luiz Gama Nogueira-Filho https://orcid.org/0000-0001-5392-0773 Paola Pereira das Neves Snoeck https://orcid.org/0000-0003-4445-8630

\section{RESUMO}

Queixada (Tayassu pecari) é um mamífero neotropical, classificado como vulnerável devido à caça e à destruição de seu habitat. Em razão das dificuldades na reprodução em cativeiro, técnicas de reprodução assistida podem ser aplicadas em programas de repovoamento da espécie. Dessa forma, objetivou-se identificar o melhor protocolo de teste hiposmótico (HOST) para avaliar a integridade funcional dos espermatozoides de queixada. O sêmen de quatro machos adultos foi coletado com auxílio de eletroejaculador após contenção física e protocolo de sedação e anestesia. $\mathrm{O}$ sêmen foi avaliado quanto às características macro e microscópicas e diluído nas seguintes soluções hiposmóticas: água destilada $(0 \mathrm{mOsmol} / \mathrm{L})$, sacarose $(50,100,150 \mathrm{mOsm} / \mathrm{L}) \mathrm{e}$ frutose $(50,100,150 \mathrm{mOsm} / \mathrm{L})$. Cada amostra foi incubada em duplicata, e uma sofreu fixação em solução de citrato de sódio formolizado a 4\%. Duzentos espermatozoides foram avaliados por amostra e classificados em reativos ou não ao HOST. Todas as soluções testadas foram semelhantes em identificar o percentual de espermatozoides reativos, independentemente de a amostra ser ou não fixada $(\mathrm{P}>0,05)$. Dessa forma, pode-se usar água destilada como HOST por este apresentar resultados similares e por ser um teste mais barato.

Palavras-chave: queixada, sêmen, teste hiposmótico

\begin{abstract}
White-lipped peccary (Tayassu pecari) is a neotropical mammal classified as vulnerable due to overhunting and habitat destruction. Due to the low reproduction success in captivity, assisted reproduction techniques can be used in re-stocking programs. Therefore, we aimed to identify the best hyposmotic swelling test (HOST) to evaluate the functional integrity of peccary sperm. Semen samples of four adult males were collected with the aid of an electroejaculator after physical contention, sedation and anesthesia protocols. The semen was evaluated for macro and microscopic characteristics and diluted in the following hyposmotic solutions: distilled water (OmOsmol/L), sucrose (50, 100, 150mOsm/L) and fructose (50, 100, 150mOsm/L). Each sample was incubated in duplicate and one was fixed in 4\% formalized sodium citrate solution. Two hundred spermatozoa were evaluated from each sample and classified as reactive or not-reactive to HOST. There were similar proportions of reactive and functional sperm regardless of whether the sample was fixed or not fixed $(P>0.05)$. Therefore, distilled water can be used as HOST to evaluate the functional integrity of white-lipped peccary sperm because it shows similar results and it is a cheaper test.
\end{abstract}

Keywords: white-lipped peccary, semen, hyposmotic test

\section{INTRODUÇÃO}

O queixada (Tayassu pecari) é um mamífero neotropical ameaçado de extinção devido à caça e à destruição de seu habitat, sendo classificado como vulnerável pela União Internacional para Conservação da Natureza (IUCN) (Keuroghilian et al., 2013). Para reverter esse processo, estão sendo realizadas tentativas de criação de

Recebido em 12 de dezembro de 2017

Aceito em 17 de maio de 2018

E-mail: celso_barrosmv@hotmail.com queixadas em cativeiro para programas de repovoamento (Nogueira et al., 2017). Porém, a fertilidade do reprodutor criado em cativeiro precisa ser conhecida, pois alguns machos apresentam infertilidade (Sowls, 1997), a fim de permitir a adoção de técnicas apropriadas de reprodução assistida.

Uma das características espermáticas que devem ser mantidas para gerar bons resultados quando 
da utilização de técnicas de conservação de sêmen para reprodução assistida é a integridade de membrana plasmática (Perez-Llano et al., 2001). A integridade da membrana está envolvida em vários processos fisiológicos de manutenção e sobrevivência dos espermatozoides no sistema genital feminino (Gwathmey et al., 2006). Além disso, atua como uma barreira seletiva entre os componentes dos ambientes intracelular e extracelular, participando do processo de capacitação espermática, da reação acrossomal, da ligação com a zona pelúcida e da fusão dos gametas (Mocé e Graham, 2008).

Para avaliação da funcionalidade da membrana plasmática do espermatozoide humano, Jeyendran et al. (1984) desenvolveram um teste em que a célula era submetida a diferentes osmolaridades. Observaram que os espermatozoides diluídos em soluções com baixa osmolaridade, para atingirem o equilíbrio osmótico entre os meios extra e intracelular, sofriam turgidez pela entrada de água na célula. O transporte de fluido por meio da membrana era percebido pela resposta de dobramento e ou enrolamento da cauda, indicando integridade e funcionalidade da membrana (Neild et al., 1999). Por isso, o teste foi denominado de hiposmótico (HOST).

O HOST é um dos métodos mais simples e rápidos para avaliar a funcionalidade da membrana plasmática dos espermatozoides. Além disso, o teste é bom preditor de fertilidade, já que a fertilização in vivo do oócito não acontece se a membrana plasmática do espermatozoide estiver bioquimicamente inativa (Perez-Llano et al., 2001; Padrik et al., 2012). Correa et al. (1997) descreveram uma alta correlação entre o percentual de espermatozoides funcionalmente íntegros e a fertilidade. Por isso, o HOST pode ser utilizado como um método complementar na análise da potentia generandi de um reprodutor (Padrik et al., 2012).

Estudos com HOST para avaliar a integridade funcional da membrana de espermatozoides já foram descritos em espécies das famílias Suidae e Tayassuidae, como nos suínos domésticos (Lechniak et al., 2002), javalis (Sus scrofa) (Rodriguez-Gil e Rigau, 1996) e catetos (Pecari tajacu) (Santos et al., 2013) devido ao interesse na produção animal. Entretanto, na literatura consultada, não existe relato da aplicação do HOST em queixada. Portanto, objetivou-se definir qual a melhor solução e osmolaridade para avaliar a integridade funcional dos espermatozoides de queixada, tendo em vista o potencial desses animais de serem utilizados em criatórios comerciais para produção de proteína animal de qualidade.

\section{MATERIAL E MÉTODOS}

Foram utilizados quatro queixadas, machos, adultos, com peso médio de $37,8 \pm 4,8 \mathrm{~kg}$, do criadouro científico de animais silvestres da Universidade Estadual de Santa Cruz (Uesc), Ilhéus, BA, Brasil (14 47' 47" S; 39 10' 20" O). Os animais foram alocados individualmente em baias metabólicas com $11,3 \mathrm{~m}^{2}$. Nesses recintos, eles foram alimentados duas vezes ao dia, com dieta composta pela mistura de milho, farelo de soja e suplementos minerais, proporcionando $120 \mathrm{~g} / \mathrm{kg}$ de proteína bruta e $14,5 \mathrm{MJ} / \mathrm{kg}$ de energia digestível, com base na matéria seca, seguindo as recomendações de Nogueira-Filho et al. (2014), e água fornecida ad libitum. Os protocolos experimentais aplicados no presente estudo foram aprovados pela Comissão de Ética no Uso de Animais (Ceua - Uesc), protocolo $n^{\circ}$. 031/16.

Para a coleta de sêmen, os animais foram contidos com auxílio de puçá e submetidos ao protocolo anestésico, com associação de acepromazina e cetamina depois de jejum alimentar por 12 horas e hídrico por seis horas. Foi administrada acepromazina, na dose de $0,2 \mathrm{mg} / \mathrm{kg}$, por via intramuscular (IM), e cetamina, na dose de $5 \mathrm{mg} / \mathrm{kg}$, por via IM, conforme descrito por Kahwage et al. (2010), que realizaram procedimentos similares para coleta de sêmen de cateto, um pecari da mesma família (Tayassuidade) e com características morfológicas e fisiológicas similares às do queixada (Sowls, 1997).

Depois de anestesiados, cinco minutos antes da coleta, foram administrados 5UI de ocitocina por via intravenosa (IV). Como método de coleta, foi utilizado um eletroejaculador (modelo Eletrogen $\left.{ }^{\circledR}\right)$, dotado de probe com dois eletrodos lineares conectados a uma fonte de $12 \mathrm{~V}$, usandose o protocolo descrito para catetos (Castelo et al., 2010). Foi obtido um ejaculado por animal, totalizando quatro ejaculados para o estudo, os 
quais foram acondicionados em tubos plásticos previamente identificados. Transcorrida a coleta, as amostras foram colocadas em banho-maria à temperatura de $37^{\circ} \mathrm{C}$, para avaliação macroscópica e microscópica do sêmen. O volume de sêmen foi registrado em $\mu \mathrm{L}$, com auxílio de micropipeta de volume ajustável, e a concentração espermática foi avaliada por meio da câmara de Neubauer.

Os parâmetros de movimento espermático foram avaliados por sistema computadorizado. Os padrões utilizados para o ajuste do equipamento foram baseados nas recomendações do programa Sperm Class Analyser® (Microptics S.L, v.5.2, Barcelona, Espanha) para análise de espermatozoides de suíno, descritas a seguir: 25 imagens / segundo com 25Hz; tamanho de partícula capturado entre 10 e $80 \mu \mathrm{m} / \mathrm{m}^{2}$; espermatozoides considerados imóveis $<10 \mu \mathrm{m} / \mathrm{s}$, lentos $<25 \mu \mathrm{m} / \mathrm{s}$, médios $>25 \mu \mathrm{m} / \mathrm{s}$ e $<45 \mu \mathrm{m} / \mathrm{s}$ e rápidos acima de $45 \mu \mathrm{m} / \mathrm{s}$. Foram avaliados os seguintes parâmetros seminais: motilidade total (MT), motilidade progressiva (MP), velocidade curvilinear (VCL), velocidade linear progressiva (VSL) e velocidade média do trajeto (VAP), expressas em micrômetros por segundo $(\mu \mathrm{m} / \mathrm{s})$.

Para avaliação da morfologia espermática, uma amostra de sêmen fresco de todos os animais foi fixada em citrato de sódio formolizado a $4 \%$ antes do HOST. Essas avaliações foram realizadas em microscópio de contraste de fase (x1000), em preparação úmida entre lâmina e lamínula. Foram avaliadas 200 células e classificadas de acordo com a região da alteração morfológica encontrada no espermatozoide.

Para estabelecer o melhor protocolo de HOST para queixada, foram testadas as seguintes soluções e osmolaridades: água destilada (0mOsmol/L), sacarose $(50,100,150 \mathrm{mOsmol} / \mathrm{L})$ e frutose $(50,100,150 \mathrm{mOsmol} / \mathrm{L})$. Em todos os grupos experimentais, foram adicionados $10 \mu \mathrm{L}$ de sêmen em $90 \mu \mathrm{L}$ de solução hiposmótica, que foi incubada em banho seco a $37^{\circ} \mathrm{C}$ por 40 minutos (Santos et al., 2013). Com o intuito de verificar o efeito da solução fixadora no percentual de reativos ao HOST, as amostras foram feitas em duplicatas para todos os grupos experimentais, sendo uma de cada tratamento fixada após o período de incubação com $45 \mu \mathrm{L}$ de citrato de sódio formolizado a $4 \%$.
Após o período de incubação, a leitura do percentual de reativos ao HOST das amostras fixadas e não fixadas foi realizada em microscópio óptico comum (Microscópio Olympus ${ }^{\circledR}$ CX21) por três diferentes técnicos, na objetiva de imersão (x1000), em preparação úmida entre lâmina e lamínula, coradas com rosa bengala a 3\%. Um total de 200 espermatozoides foram avaliados em pelo menos cinco campos e classificados em reativos ou não reativos ao HOST, com base na presença ou ausência de caudas dobradas e/ou enroladas, respectivamente (Jeyendran et al., 1984). Para cálculo do percentual de espermatozoides com membrana funcionalmente íntegra, foi empregada a fórmula descrita por Melo e Henry (1999), em que a porcentagem de espermatozoides com defeitos de cauda (com base na avaliação da morfologia) foi subtraída da porcentagem de espermatozoides reativos ao HOST.

Para análise estatística, foi usado o delineamento de blocos ao acaso, considerando cada indivíduo como um bloco. Foi aplicada ANOVA para comparar o percentual de espermatozoides funcionalmente íntegros entre as soluções testadas. Todos os pressupostos de normalidade e homocedasticidade foram testados e estavam adequados. Foi aplicado o teste de correlação de Spearman para verificar a existência de correlação entre a funcionalidade da membrana (percentual de íntegros obtidos no HOST) com os parâmetros seminais analisados. Todas as análises foram feitas com o auxílio do R Core Team (2016).

\section{RESULTADOS}

Os ejaculados apresentaram volume médio de $375,0 \mu \mathrm{L}$ e concentração média de $885,25 \times 10^{6}$ espermatozoides/mL. Os espermatozoides de queixada apresentaram motilidade total média de $66,4( \pm 25,4) \%$, motilidade progressiva média de $30,7( \pm 27,0) \%$, VCL média de $42,7( \pm 15,8)$ $\mu \mathrm{m} / \mathrm{s}$, VSL média de $14,5( \pm 10,0) \mu \mathrm{m} / \mathrm{s}$, VAP média de 23,4 $( \pm 12,8) \mu \mathrm{m} / \mathrm{s}$.

O percentual médio de espermatozoides morfologicamente normais foi de 69,0 ( $\pm 12,9)$ $\%$. O percentual médio de alterações morfológicas encontradas por região do espermatozoide foi de: 0,0 no acrossoma, 1,9 ( \pm $1,9) \%$ na cabeça, 7,6 ( $\pm 5,5) \%$ de gota citoplasmática proximal, $6,5( \pm 5,2) \%$ de gota citoplasmática distal, $0,5( \pm 0,5) \%$ na peça 
intermediária, $0,75( \pm 0,9) \%$ na peça principal, $0,25( \pm 0,5) \%$ na peça terminal e $13,5( \pm 22,3)$ $\%$ envolvendo a cauda como um todo. Não foram observadas diferenças $(\mathrm{P}>0,05)$ no percentual de espermatozoides reativos ao HOST entre as soluções hiposmóticas, a osmolaridade e a fixação ou não em citrato de sódio formolizado a $4 \%$ testadas para avaliar a integridade funcional dos espermatozoides de queixada (Tab. 1). Não foram observadas correlações entre o HOST com diferentes soluções hiposmóticas e a MT ( $r=0,40, \mathrm{P}>0,05)$, a MP $(\mathrm{r}=0,00, \mathrm{P}>0,05)$, a VCL $(r=0,40, P>0,05)$, a VSL $(r=0,40, P>0,05)$, a VAP $(r=0,00, P>0,05)$ e os espermatozoides morfologicamente normais $(\mathrm{r}=0,80, \mathrm{P}>0,05)$.

Tabela 1. Efeito da solução, da osmolaridade, da fixação ou não em citrato de sódio formolizado a $4 \%$ na integridade funcional dos espermatozoides de queixada avaliados pelo HOST

\begin{tabular}{lccc}
\hline \multicolumn{4}{c}{ Sem fixação em citrato de sódio formolizado a 4\% } \\
\hline \multirow{2}{*}{ HOST } & $\begin{array}{c}\text { Osmolaridade } \\
\text { (mOsmol/L) }\end{array}$ & $\begin{array}{c}\text { Funcionalmente } \\
\text { integros ao HOST }(\%)\end{array}$ & $\begin{array}{c}\text { Intervalo de confiança } \\
\text { de 95\% }\end{array}$ \\
\hline Água destilada & 0 & 36,0 & $(25,93 ; 46,07)$ \\
Sacarose & 50 & 36,1 & $(26,06 ; 46,19)$ \\
& 100 & 24,2 & $(14,13 ; 34,27)$ \\
Frutose & 150 & 28,6 & $(18,56 ; 38,69)$ \\
& 50 & 35,0 & $(24,93 ; 45,07)$ \\
& 100 & 30,0 & $(28,93 ; 40,07)$ \\
Água destilada & 150 & 38,4 & $(26,68 ; 46,44)$ \\
& Com fixação em citrato de sódio formolizado a 4\% & $(17,81 ; 37,94)$ \\
Sacarose & 0 & 36,8 & $(20,06 ; 40,19)$ \\
& 50 & 27,9 & $(10,31 ; 30,44)$ \\
Frutose & 100 & 30,1 & $(26,93 ; 47,07)$ \\
& 150 & 20,4 & $(11,68 ; 31,82)$ \\
\hline
\end{tabular}

$\mathrm{Na}$ Fig. 1, é possível visualizar os espermatozoides reativos, com reflexão distal de peça intermediária, e os não reativos ao HOST, apresentando a cauda reta.

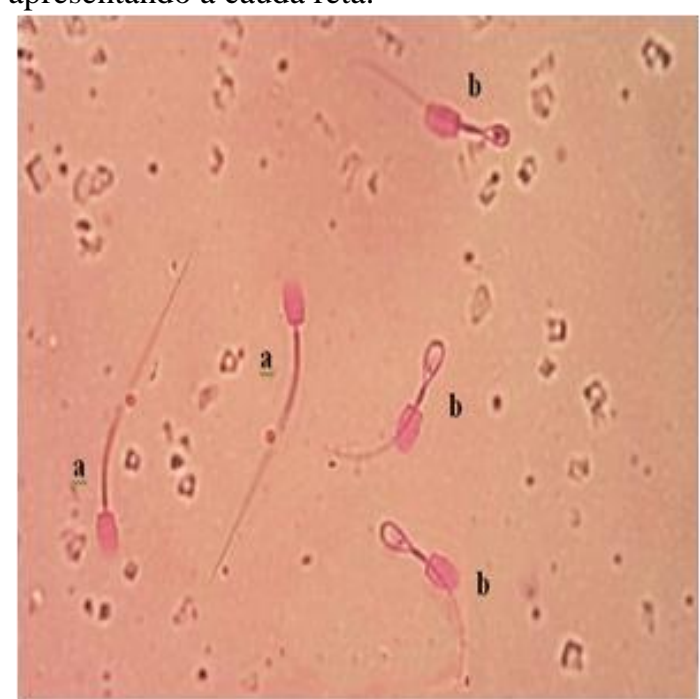

Figura 1. Espermatozoides de queixada (a) não reativos e (b) reativos ao teste hiposmótico.

\section{DISCUSSÃO}

Não foi verificada superioridade entre o HOST com água destilada (0mOsmol/L) ou soluções de sacarose e frutose (50, 100 e $150 \mathrm{mOsmol} / \mathrm{L})$, fixadas ou não em citrato de sódio formolizado a $4 \%$, sobre o percentual de espermatozoides de queixadas reativos e funcionalmente íntegros. Esse resultado é indicativo de que os espermatozoides de queixada respondem a diferentes tipos de soluções hiposmóticas à base de açúcares, bem como à água destilada e a diferentes osmolaridades. Os valores encontrados no presente estudo de reativos ao HOST ficaram entre $20,40 \%$ e $38,40 \%$, sendo superiores aos achados de Samardzija et al. (2008), que encontraram valores médios de $16,96 \%$, e similares aos achados de Lechniak et al. (2002), de $34,68 \%$, ambos em pesquisas com suínos domésticos.

Não foram encontrados outros relatos na literatura sobre qual protocolo deve ser 
empregado para avaliar a integridade funcional dos espermatozoides de queixada, embora Santos et al. (2013) tenham descrito diferentes soluções para avaliarem a integridade funcional dos espermatozoides de cateto e relatado o uso de água destilada (0mOsmol/L) e de soluções de frutose com osmolaridade de 50, 100, 150 e $200 \mathrm{mOsmol} / \mathrm{L}$, sem fixação em formol. No presente estudo, foi possível verificar que os espermatozoides de queixada apresentaram resposta ao HOST semelhante aos espermatozoides do cateto, até a osmolaridade testada, que variou de 0 a $150 \mathrm{mOsmol} / \mathrm{L}$. Percebe-se que os espermatozoides dos Tayassuidae (queixadas e catetos) podem ser submetidos a uma ampla faixa de osmolaridade quando comparados aos espermatozoides dos suínos domésticos, os quais respondem melhor quando incubados em soluções com osmolaridade de $100 \mathrm{mOsmol} / \mathrm{L}$ preparadas com frutose (Matson et al., 2009).

Não foi verificada redução linear significativa do percentual de espermatozoides funcionalmente íntegros em decorrência do aumento da osmolaridade $(0,50,100$ e $150 \mathrm{mOsm} / \mathrm{L})$ da solução hiposmótica, como relatado por Santos et al. (2013), que observaram redução expressiva do percentual de funcionalmente íntegros quando aumentaram a osmolaridade da solução de 150 para 200mOsmol/L. Para os suínos domésticos, o percentual máximo de reativos ao teste ocorre em amostras incubadas em solução de $100 \mathrm{mOsmol} / \mathrm{L}$ em comparação com soluções de 75 ou $125 \mathrm{mOsmol} / \mathrm{L}$ (Matson et al., 2009). Isso é indicativo e reafirma que os espermatozoides dos Tayassuidae possuem maior tolerância à variação de osmolaridade da solução do que os espermatozoides de suínos.

Como não houve diferença significativa entre as soluções hiposmóticas, a água destilada poderá ser usada como teste de escolha, pois não haverá necessidade de diluição com nenhum soluto e dosagem de osmolaridade. Por isso, o teste hiposmótico com água destilada apresenta a vantagem de baixo custo e fácil manuseio, comparado ao emprego do HOST usando soluções à base de açúcares convencionalmente utilizadas (Quintela et al., 2010) ou mesmo à base de eletrólitos.

Em garanhões, a água destilada provou ser mais eficaz do que outras soluções à base de açúcar para detecção da integridade funcional de espermatozoides (Dell'Aqua et al., 2002), e também é possível identificar maior porcentagem de espermatozoides com cauda fortemente enrolada, reação ao HOST mais fácil de ser identificada na microscopia (Snoeck et al., 2014). Além disso, a membrana do espermatozoide equino apresenta alta permeabilidade à água, devido à presença de uma membrana porosa e canais de água (Neild et al., 1999), o que pode explicar a superioridade dos testes de avaliação de integridade funcional da célula usando a água destilada, embora ainda não seja possível especular que essas características estejam presentes nos espermatozoides de Tayassuidae.

Estudos relataram uma variação individual acentuada na resposta ao HOST em suínos, o que é atribuído a diferenças na composição, funcionalidade e resistência dos espermatozoides (Pérez-Llano et al., 2001). Peixoto et al. (2012) relataram a existência de grande variação de qualidade seminal entre indivíduos e entre ejaculados do mesmo indivíduo depois da avaliação do sêmen fresco de cateto. Essa variação individual também foi percebida no sêmen coletado dos queixadas, e isso influencia no resultado do percentual de reativos ao HOST, tendo em vista que ejaculados com qualidade ruim e alto percentual de alterações morfológicas de cauda podem resultar em baixo percentual de espermatozoides considerados funcionalmente íntegros.

Não foi verificada influência da fixação em citrato de sódio formolizado nas amostras analisadas, o que indica que as amostras podem ser avaliadas imediatamente após a incubação ou em outro momento após a fixação delas em solução contendo formaldeído. O formaldeído possui rápida penetração no interior das células e atua desnaturando as proteínas presentes na membrana plasmática (Mason e O’Leary, 1991). Essa desnaturação proteica promove alterações na permeabilidade da membrana, dificultando ou impedindo o transporte de água para o interior da célula (Zhu et al., 2002). Com base neste mecanismo de ação, a reação hiposmótica foi interrompida quando as amostras incubadas passaram pela fixação em solução de citrato de sódio formolizado a $4 \%$ e, por isso, não foi observada superioridade do HOST fixado sobre o HOST não fixado, principalmente porque a 
leitura do percentual de reativos foi realizada imediatamente após a incubação nas duas amostras, antes ou depois da fixação.

A fixação em solução de citrato de sódio formolizado a $4 \%$ não influenciou negativamente o percentual de espermatozoides funcionalmente íntegros obtidos pelo HOST, corroborando os achados de Alves et al. (2005), que também não encontraram esse efeito sobre o percentual de íntegros nos espermatozoides equino. Outros estudos mostraram que a fixação espermática causa a redução do comprimento da cabeça do espermatozoide humano em aproximadamente 15\% (Katz et al., 1986) e do espermatozoide equino em 20\% (Ball e Mohammed, 1995), embora Salviano et al. (2011) não tenham encontrado esse efeito quando estudaram espermatozoides de caprino. No entanto, é importante ressaltar que o HOST avalia as modificações de cauda e não da cabeça. Vale salientar que a fixação das amostras permite que elas sejam avaliadas em momento oportuno e não de forma imediata, como ocorre com as amostras que foram somente incubadas na solução hiposmótica. Registra-se que é possível utilizar a mesma diluição sêmen:solução, as mesmas soluções hiposmóticas e o mesmo tempo de incubação utilizado no HOST que avalia a funcionalidade de membrana de cateto (Santos et al., 2013).

No presente estudo, não foram observadas correlações significativas entre o HOST e os parâmetros seminais de movimento e morfologia espermática, corroborando com os resultados de Santos et al. (2013), no estudo de HOST em catetos, e por Perez-Llano et al. (2001), em suínos domésticos. Por outro lado, Perez-Llano et al. (2001) relataram haver correlação entre o HOST e a fertilidade in vivo em suínos domésticos. Dessa forma, a existência de correlação entre o HOST e a fertilidade deve ser investigada na família Tayassuidae.

\section{CONCLUSÃO}

A avaliação da integridade funcional da membrana plasmática dos espermatozoides de queixada pode ser realizada com testes hiposmóticos, utilizando-se soluções preparadas com sacarose ou frutose entre 50 e $150 \mathrm{mOsmol} / \mathrm{L}$ e água destilada com ou sem fixação em citrato de sódio formolizado a $4 \%$.
Os resultados obtidos no presente estudo, contudo, indicam a possibilidade do uso apenas de água destilada por apresentar resultados similares e ser um teste mais barato e não necessitar de avaliação da osmolaridade da solução.

\section{REFERÊNCIAS}

ALVES, S.G.G.; RIBEIRO FILHO, A.L.; SNOECK, P.P.N. et al. Efeito da solução, da fixação em formolsalina e do tempo de incubação sobre os resultados do teste hiposmótico para sêmen equino congelado. Ciênc. Anim. Bras., v.6, p.219-225, 2005.

BALL, B.A.; MOHAMMED, H.O. Morphometry of stallion spermatozoa by computer assisted image analysis. Theriogenology, v.49, p.367-377, 1995.

CASTELO, T.S.; BEZERRA, F.S.B.; LIMA, G.L. $e t$ al. Effect of centrifugation and sugar supplementation on the semen cryopreservation of captive collared peccaries (Tayassu tajacu). Cryobiology, v.61, p.275279, 2010.

CORREA, J.R.; PACE, M.M.; ZAVOS, P.M. Relationships among frozen-thawed sperm characteristics assessed via the routine semen analysis, sperm functional tests and fertility of bulls in an artificial insemination program. Theriogenology, v.48, p.721-731. 1997.

DELL'AQUA JR, J.A.; PAPA, F.O.; ZAHN, F.S. et al. Novo teste osmótico de avaliação da integridade da membrana plasmática de sêmen congelado equino. Rev. Bras. Reprod. Anim., v.26, p.189-191, 2002.

GWATHMEY, T.M.; IGNOTZ, G.G.; MUELLER, J.L. et al. Bovine seminal plasma proteins PDC-109, BSP-A3, and BSP-30-kDa share functional roles in storing sperm in the oviduct. Biol. Reprod., v.75, p.501-507, 2006.

JEYENDRAN, R.S.; VAN DER VEN, H.H.; PEREZPELAEZ, M. et al. Development of an assay to assess functional integrity of the human sperm membrane and its relationship to other semen characteristics. $J$. Reprod. Fertil., v.70, p.219-228, 1984.

KAHWAGE, P.; GARCIA, A.R.; GUIMARÃES, D.A.A. et al. Biometria testicular, eletroejaculação e características seminais de caititus, Tayassu tajacu Linnaeus, 1758 (Mammalia, Artiodactyla, Tayassuidae) mantidos em cativeiro na Amazônia Oriental. Acta Amaz., v.40, p.771-778. 2010.

KATZ, D.F.; OVERSTREET, J.W.; SAMUELS, S.J. et al. Morphometric analysis of spermatozoa in the assessment of human male fertility. J. Androl., v.7, p.203-210, 1986. 
KEUROGHLIAN, A.; DESBIEZ, A.; REYNAHURTADO, R. et al. Tayassu pecari. In: IUCN red list of threatened species. Version 2013. Available in: $<\mathrm{http} / /$ www.iucnredlist.org $>$. Accessed in: 15 Dec. 2017.

LECHNIAK, D.; KEDZIERSKI, A.; STANISLAWSKI, D. The use of HOS test to evaluate membrane functionality of boar sperm capacitated in vitro. Reprod. Dom. Anim., v.37, p.379-380, 2002.

MASON, J.T.; O'LEARY, T.J. Effects of formaldehyde fixation on protein secondary structure: a calorimetric and infrared spectroscopic investigation. J. Histochem. Cytochem., v.39, p.225-229, 1991.

MATSON, P.; KAPPELLE, W.; MALECKI, I. The use of a hypo-osmotic swelling (HOS) test on sperm of the pig (Sus scrofa domesticus), emu (Dromaius novaehollandiae), Asian elephant (Elephas maximus), hamadryas baboon (Papio hamadryas hamadryas), and central rock rat (Zyzomys pedunculatus). Reprod. Biol., v.9, p.181-187, 2009.

MELO, M.I.V.; HENRY, M. Teste hiposmótico na avaliação de sêmen equino. Arq. Bras. Med. Vet. Zootec., v.51, p.71-78, 1999.

MOCÉ, E.; GRAHAM, J.K. In vitro evaluation of sperm quality. Anim. Reprod. Sci., v.105, p.104-118. 2008.

NEILD, D.; CHAVES, G.; FLORES, M. et al. Hypoosmotic test in equine spermatozoa. Theriogenology, v.51, p.721-727, 1999.

NOGUEIRA, S.S.C.; REIS, A.M.; MARSARO, S.G. et al. The defensive behavioral patterns of captive white-lipped and collared peccary (Mammalia, Tayassuidae): an approach for conservation of the species. Acta Ethol., v.20, p.127-136, 2017.

NOGUEIRA-FILHO, S.L.G.; BORGES, R.M.; MENDES, A. et al. Nitrogen requirements of whitelipped peccary (Mammalia, Tayassuidae). Zoo Biol., v.33, p.320-326, 2014.

PADRIK, P.; HALLAP, T.; KAART, T. et al. Relationships between the results of hypo-osmotic swelling tests, sperm motility, and fertility in Estonian Holstein dairy bulls. Czech J. Anim. Sci., v.57, p.490497, 2012.

PEIXOTO, G.C.X.; SILVA, M.A.; CASTELO, T.S. et al. Individual variation related to testicular biometry and semen characteristics in collared peccaries (Tayassu tajacu Linnaeus, 1758). Anim. Reprod. Sci., v.134, p.191-196, 2012.
PEREZ-LLANO, B.; LORENZO, J.L.; YENES, A. et $a l$. A short hyposmotic swelling test for the prediction of boar sperm fertility. Theriogenology, v.56, p.387398,2001

QUINTELA, A.T.; OLIVEIRA, I.R.S.; SOUZA, A.O. et al. Water-induced hypo-osmotic test for the evaluation of canine sperm membrane integrity. Anim. Reprod., v.7, p.70-74, 2010.

$\mathrm{R}$ CORE team: a language and environment for statistical computing. $\mathrm{r}$ foundation for statistical computing. Vienna: R Foundation for Statistical Computing, 2016.

RODRIGUEZ-GIL, J.E.; RIGAU, T. Effects of ouabain on the response to osmotic changes in dog and boar spermatozoa. Theriogenology, v.45, p.873-883, 1996.

SALVIANO, M.B.; SOUZA, J.A.T.; VIDIGAL, K.F. Efeito da fixação do sêmen pós-teste hiposmótico para avaliação da membrana espermática de caprinos. Rev. Cient. Elet. Med. Vet., v.16, p.1-12, 2011.

SAMARDZIJA, M.; DOBRANIC, T.; KRUSLIN, S. et al. The use of the hypoosmotic swelling test and supravital staining in evaluation of sperm quality in boars. Vet. Arch., v.78, p.279-287, 2008.

SANTOS, E.A.A.; SOUSA, P.C.; PEIXOTO, G.C.X. et al. Establishing the hypoosmotic swelling test for sperm analysis in collared peccaries (Pecari tajacu). Arq. Bras. Med. Vet. Zootec., v.65, p.1257-1260, 2013.

SNOECK, P.P.N.; MELO, M.I.; ALVES, S.G.G. et al. Qual é o teste hiposmótico mais indicado para avaliar a integridade funcional de espermatozoides equino criopreservados? Rev. Bras. Med. Vet., v.36, p.355361, 2014.

SOWLS, L.K. Javelinas and other peccaries: their biology, management, and use. 20.ed. Texas: College Station, 1997. 325p.

ZHU, F.; TAJKHORSHID, E.; SCHULTEN, K. Pressure-induced water transport in membrane channels studied bymolecular dynamics. Biophys. J., v.83, p.154-160, 2002. 